\title{
Indicios, lecturas indiciarias, estrategia indiciaria y saberes populares. una hipótesis sobre los límites de la racionalidad burguesa moderna.
}

Carlos Antonio Aguirre Rojas*

I

El conocimiento de todos los hechos humanos en el pasado, y de la mayoría de ellos en el presente, tiene como primera característica la de ser (según la feliz expresión de François Simiand) un conocimiento por medio de indicios.(BLOCH, 1941-1943)

1. El hoy célebre ensayo metodológico escrito por Carlo Ginzburg, y titulado "Spie. Radici di un paradigma indiziario", fue gestado y madurado intelectualmente entre los años de 1976 y 1978, es decir, inmediatamente después de la publicación del hoy célebre libro El queso y los gusanos, que habiendo sido publicado en italiano en 1976, es hoy, sin duda alguna, el libro más leído, comentado, criticado y difundido de Carlo Ginzburg en todo el mundo. Ubicado entonces, en un primer nivel, como un ensayo que extrae a nivel epistemológico general, algunas de las principales lecciones de método derivadas de esta misma obra El queso y los gusanos, pero al mismo tiempo y de modo más general, como una reflexión global acerca del método y la perspectiva aprendidas y desarrolladas por el propio Ginzburg, a lo largo de todo su periplo intelectual recorrido hasta ese momento, este ensayo de "Indicios" estaba destinado, desde su primera publicación, a una fortuna que es, en muchos sentidos, realmente excepcional.

Así, este texto apareció publicado por vez primera en 1978 en la Rivista di Storia Contemporánea, para luego ser republicado en 1979, en una versión considerablemente más amplia y desarrollada, en el libro titulado Crisi della

\footnotetext{
* Centro de Investigações Sociais/ Universidad Autonoma de México

! Sobre la contribución que El queso y los gusanos representa para el campo de la historia cultural, cfr. nuestro ensayo, Carlos Antonio Aguirre Rojas, "El queso y los gusanos: un modelo de historia crítica para el análisis de la cultura de las clases subalternas", incluido en nuestro libro Retratos para la Historia. Ensayos de Contrabistoria Intelectual, Ed. Contrahistorias, México, 2006.
} 
Ragione?. Y desde estas primeras ediciones italianas, este ensayo de Ginzburg despertó un enorme interés y toda una serie de vivas polémicas, primero en todo el ámbito intelectual italiano, pero después y mediante sus sucesivas traducciones a otras lenguas, también en todo el mundo académico europeo, e incluso en toda la historiografía y las ciencias sociales del mundo entero, para terminar convirtiéndose hoy, en este año de 2006, en el más importante ensayo de metodología histórica escrito en los últimos cuarenta y cinco años, sólo comparable por su relevancia y sus profundos impactos intelectuales, dentro de la historiografía y las ciencias sociales del siglo XX, con el también excepcional ensayo de Fernand Braudel sobre "Historia y ciencias sociales. La larga duración", publicado en 1958.

Porque desde su primera aparición, este artículo comenzó a suscitar de inmediato múltiples comentarios, tanto críticos como inquisitivos o laudatorios, generando una verdadera lluvia de iniciativas en las que Carlo Ginzburg era invitado a exponer, debatir, ahondar o defender las tesis de su ensayo, 10 mismo en Mesas Redondas, Conferencias o Seminarios de las más diversas Universidades Italianas, que en los más distintos foros académicos e intelectuales.

Vivo interés y enorme difusión de este ensayo que, más adelante, adquirió una dimensión europea y luego mundial, mediante las distintas traducciones del texto en diferentes idiomas, a lo que hay que agregar las reediciones de este mismo artículo, derivadas del hecho de que en 1986, fue incluido dentro del libro Mitos, Emblemas, Indicios, libro que a su vez ha sido ya traducido a once idiomas en todo el mundo 3 .

\footnotetext{
2 Las referencias precisas de estas ediciones son: bajo el título "Spie. Radici di un paradigma scientífico", fue publicado en la Rivista di Storia Contemporánea, vol. 7, 1978, pp. 1-14, y bajo el título "Spie. Radici di un paradigma indiziario" en el libro colectivo Crisi de la Ragione, Ed. Einaudi, 1979, pp. 59-106. Vale la pena subrayar el hecho de que después de esa primera edición italiana, más reducida, se publicó también la versión recién mencionada del libro, mucho más amplia, aunque sin notas, en una revista italiana de gran circulación, Ombre Rosse, lo que amplió la difusión de este ensayo entre el gran público italiano, y coadỵuó a su mayor y más inmediato impacto intelectual, dentro de los círculos académicos y culturales en general, de la Italia de esos años.

3 La lista precisa de estas traducciones del ensayo es la siguiente: de la primera versión del ensayo, la de 1978, hay una traducción holandesa de 1978, y una inglesa de 1979. De la versión más amplia, la del libro de 1979, hay dos traducciones al inglés (1980 y 1983), al alemán (1980), al francés (1980), dos al holandés (ambas en 1981), al sueco (1983), seis al español (1982, 1983, 1989, 1995, 2003, 2004), dos al japonés (1986 y 1990), al danés (1986), al ruso (1994), dos al coreano (1994 y 2000) y al griego (1996). Todas estas, sin contar las versiones incluidas en las distintas traducciones del libro Mitos, Emblemas, Indicios, que fue publicado
} 
Así, mediante estas múltiples traducciones y reediciones, este ensayo de Carlo Ginzburg "ha hecho mundo", difundiéndose en el seno de todas las historiografías nacionales del planeta y provocando, también en escala planetaria, las más diversas lecturas y las más variadas interpretaciones -y en muchas ocasiones, las más absurdas y estrambóticas malas interpretaciones-, para convertirse en un texto que hoy es uno de los referentes metodológicos imprescindibles, dentro de la formación de todo historiador que esté mínimamente actualizado respecto de los desarrollos principales de la historiografía mundial actual.

Escrito que ha tenido entonces un impacto mundial tan extraordinario, y un abanico de ecos y reacciones tan multifacético, que explica el hecho de que, sólo dentro del mundo hispanoparlante, haya ya conocido siete diferentes ediciones $^{4}$, además de contar entre sus innumerables lectores y comentadores, nada más y nada menos que al propio Subcomandante Insurgente Marcos, vocero oficial del digno movimiento indígena neozapatista mexicano 5 .

Ecos e irradiación realmente excepcionales, que están a tono con la

en italiano en 1986 y que incluye también este ensayo de "Indicios", traducciones que abarcan dos ediciones en alemán (la primera de 1983, anterior a la propia edición italiana de 1986, y otra edición de 1995), al japonés (1988), al holandés (1988), al francés (1989), al portugués (1989), al español (1989), al sueco (1989), dos al inglés (1989 y 1999), al finlandés (1996), al danés (1999) y al ruso (2004). Es decir que este ensayo de Carlo Ginzburg ha conocido, en versiones reducidas o extensas, cuatro distintas ediciones en italiano y treinta y cinco ediciones en trece otras diferentes lenguas (aunque ello, sin contar las reediciones de cada uno de los libros mencionados en esta lista). A partir de esto es lógico, aunque importante de subrayar, el hecho de que este ensayo de "Spie" es, sin duda alguna, el más traducido y el más difundido de entre todos los artículos que ha escrito Carlo Ginzburg hasta el día de hoy. Para todos estos datos, cfr. el libro coordinado por Aldo Colonnello y Andrea del Col, Uno storico, un mugnaio, un libro. Carlo Ginzburg. Il formaggio e ivermi, 1976-2002, Ed. Università di Trieste, Trieste, 2003, específicamente la 'Bibliografía de Carlo Ginzburg', incluida en las páginas 167-191, y también el fascículo titulado Premi "Antonio Feltrinelli" 2005. Estratto, Ed. Accademia Nazionale dei Lincei, 2005, pp. 34-44.

4 Estas siete traducciones son: en la revista El Viejo Topo, num. 68, 1982; en el libro Crisis de la razón, Ed. Siglo XXI, México, 1983; en el libro Mitos, Emblemas, Indicios, Ed. Gedisa, Barcelona, 1989; en el libro El signo de los tres, Ed. Lumen, Barcelona, 1989; en el libro Discusión sobre la bistoria, Ed. Taurus, México, 1995; en el libro Tentativas, Ed. Universidad Michoacana, Morelia, 2003; y en este mismo libro Tentativas, Ed. Prohistoria, Rosario, 2004. Vale la pena subrayar el hecho de que la traducción incluida en las dos versiones de este libro de Tentativas fue revisada y aceptada directamente por el propio Carlo Ginzburg, además de haber tenido en cuenta todas las traducciones anteriores.

5 La lectura del Subcomandante Marcos del ensayo de Carlo Ginzburg, se debió a que el mismo le fue enviado por Adolfo Gilly. Ello suscitó varias interesantes críticas de Marcos al ensayo, y una larga respuesta de Adolfo Gilly, las que fueron inicialmente publicadas en la revista Viento del Sur, num. 8, México, 1995, y luego reeditadas en el libro Discusión sobre la bistoria antes mencionado. 
propia reacción que suscitó, en su mismo autor, este enorme éxito de su ensayo "Indicios". Como lo ha declarado en varias ocasiones, y marchando en este punto una vez más a contracorriente de los hábitos tradicionales y mayoritarios del mundo académico, la respuesta de Carlo Ginzburg frente a esta amplísima e inusitada recepción de su artículo, fue la de tomar distancia radicalmente respecto del término de "paradigma indiciario", negándose a utilizarlo nuevamente durante más de veinte años, y rechazando explícitamente el convertirse en el "padre" o "especialista" o "teórico" mundial de ese mismo paradigma indiciario.

Lo que sin embargo, no impidió como él mismo lo reconoce, que las tesis e hipótesis de dicho ensayo siguieran animando en profundidad todo su trabajo intelectual posterior, pero también, y más allá de su propia voluntad, el hecho de que en el mundo entero, la tesis de este paradigma indiciario se asocie inevitable y recurrentemente con el nombre del también autor del igualmente célebre y difundido libro El queso y los gusanos ${ }^{6}$.

Éxito inusitado y periplos excepcionales de este fundamental ensayo de "Indicios", que nos llevan a preguntarnos acerca de las razones específicas de esta misma difusión planetaria y de estos prolongados ecos intelectuales, tanto dentro de la historiografía mundial contemporánea, como también dentro de un sector importante de la comunidad internacional de científicos sociales, que incluye lo mismo a psicólogos que a filósofos, pasando por antropólogos, teóricos de la literatura, epistemólogos y lingüistas, entre otros varios. Razones del singular éxito intelectual de este texto de "Indicios", que vale la pena revisar con más detalle ahora.

6 Después de 1979, Ginzburg no volverá a utilizar el término de paradigma indiciario hasta el año 2000, cuando vuelve a referirlo en la Introducción de su libro No Island is an Island, Ed. Columbia University Press, New York, 2000, p. XIII. Su distanciamiento explícito del término, se había manifestado ya en la entrevista que le concedió a su gran amigo Adriano Sofri en 1982, y que fue publicada en el diario Lotta Continua del 17 de febrero de 1982 (y en español, en el libro Ensayos sobre microbistoria, Ed. Jitanjáfora, Morelia, 2002, y en la revista Ruptura, num. 10-11, Villahermosa, 2002. Véase también su ensayo "Reflexiones sobre una hipótesis. El paradigma indiciario veinticinco años después", incluido en este mismo número de Contrabistorias. En la entrevista de 1982, Ginzburg le responde a Adriano Sofri, que afirma que este ensayo de "Indicios" ha convertido al propio Ginzburg en un verdadero 'Maitre à penser' lo siguiente: "Me he dado cuenta, es verdad, de que existía una cierta presión, proveniente de muchas partes, y que era a veces declarada y a veces no, para que me transformase en el ideólogo oficial del 'paradigma indiciario'. Esta idea no me gustaba para nada, y he tratado de escabullirme hacia otra parte, moviéndome un poco, y entonces me he puesto a escribir el libro sobre Piero". (Cfr. Ensayo sobre microbistoria, citado, p. 223). 
2. Si queremos comprender cabalmente, estas razones esenciales de esos vastos ecos y de ese enorme impacto exitoso de "Indicios", resulta útil compararlo nuevamente, con el igualmente célebre ensayo braudeliano sobre "Historia y ciencias sociales. La larga duración". Pues una primera razón importante del hondo efecto de ambos ensayos, estriba en que en ellos se hace conciente y explícito todo un específico modo de aproximación y luego de conocimiento de la realidad, modo que al ser teorizado y establecido en sus implicaciones principales, por vez primera dentro de la bistoria, revela entonces todas sus grandes potencialidades cognoscitivas y heurísticas.

Porque el mérito tanto de Fernand Braudel en 1958, como y luego de Carlo Ginzburg en 1978-79, no está en haber "descubierto", o "inventado", o "creado" por vez primera esos específicos modos de conocimiento de la realidad o estrategias epistemológicas de aprebensión de lo real, sino más bien en baber becho explícitos y en haber teorizado dichos modos o estrategias, incorporándolos, aquí sí por vez primera, dentro del abanico consciente de las posibles formas de cognoscibilidad de la realidad objetiva, en este caso histórica y social en general'. Es decir, en haber llevado a cabo, dentro de las ciencias sociales, algo equivalente a lo que sucedió en el momento en que Cristóbal Colón descubrió América. Pues si bien los hombres habitaban ya este Continente desde hacía siglos y milenios, y si incluso las tierras de América habían sido ya antes conocidas tanto por los europeos como por los chinos antes de la llegada de Colón a América, sin embargo, es solamente después de los viajes de Colón que va a asumirse el hecho elemental pero fundamental de que la Tierra es

\footnotetext{
7 Y es esto lo que lleva a Braudel, por ejemplo, a decir que ha sido Marx "el primero en fabricar verdaderos modelos sociales a partir de la larga duración histórica", lo que también hicieron, según el mismo Braudel autores como Michelet, entre otros. Sobre este punto, cfr. el ensayo "Historia y Ciencias Sociales. La larga duración", incluido en el libro Escritos sobre bistoria, Ed. Fondo de Cultura Económica, México, 1991, p. 72, y también nuestro libro, Carlos Antonio Aguirre Rojas, Fernand Braudel et les sciences bumaines, Ed. L'Harmattan, París, 2004, y nuestro ensayo "Between Marx and Braudel: Making history, knowing history" en la revista Review, vol. 15, num. 2, 1992. Y también es por eso que Carlo Ginzburg afirma, con un tono en parte serio y en parte claramente irónico, que al explicitar el paradigma indiciario, había quizá afirmado una "banalidad", o después, que había dicho cosas que estaban ya en el aire o atmósfera de esa época (cfi: "Intervención sobre el paradigma indiciario", y también "Reflexiones sobre una hipótesis. El paradigma indiciario 25 años después", ambos ensayos incluidos en este mismo número de Contrabistorias). Pero, en nuestra opinión, justamente su mérito esencial reside en haber llevado a cabo esa explicitación y teorización de dichos modos del conocimiento humano, esa verdadera "toma de conciencia" de dichas estrategias cognoscitivas fundamentales.
} 
redonda, y con ello, todas las múltiples, complejas y esenciales implicaciones de esta redondez. Del mismo modo en que, gracias al texto de Fernand Braudel, los hombres asumirán por primera vez de manera consciente y orgánica la diversidad y la multiplicidad de los distintos tiempos históricos y sociales, lo mismo que después de Carlo Ginzburg, asumirán también consciente y sistemáticamente la existencia, los usos, la riqueza y las implicaciones de la aplicación del paradigma y de la estrategia indiciarios, dentro de las formas del conocimiento humano de la realidad.

Entonces, lo que el texto de "Indicios" realiza es el proceso de explicitación y teorización de una estrategia cognoscitiva de existencia milenaria y de efectos múltiples a todo lo largo y ancho de la historia. Estrategia vinculada de un modo privilegiado con el vasto universo de los saberes populares nacidos de la experiencia directa, que posee entonces alcances estrictamente universales, tanto en lo que respecta a su duración y a su extensión geográfico-espacial, como también a la variedad y riqueza de sus manifestaciones.

Pues ese conocimiento a través de "Indicios" o "Huellas" ha existido desde los tiempos de los más antiguos cazadores y hasta nuestras épocas características de los más modernos psicoanalistas, pero también lo mismo en China, Rusia, Europa o Japón, que en las montañas del Sureste mexicano, en África 0 en toda América Latina. E igualmente, manifestándose lo mismo como saber del campesino indígena rebelde que escapa a los poderosos, que como método detectivesco en la novela británica, pero también como método policiaco de control en la India, o como apoyo logístico de los ejércitos de la contrainsurgencia colombiana, o salvadoreña, o mexicana o norteamericana.

Extensión universal en términos temporales, espaciales y dimensionales de este conocimiento indiciario que, sin embargo, no había sido explicitada y teorizada de modo orgánico y sistemático antes del ensayo de Carlo Ginzburg. Lo que este último hará, desarrollando además algunas de sus principales implicaciones, en primer lugar para la ciencia histórica, y luego para las ciencias sociales en general, pero también y finalmente, para el propio conocimiento humano en general.

3. Asumir de manera orgánica esas implicaciones del conocimiento apoyado en los indicios, nos lleva entonces a modificar, de manera sustantiva 
y fundamental, nuestras concepciones habituales respecto de lo que es, por ejemplo, el objeto general de estudio de la ciencia histórica -y por esta vía, el objeto mismo de las ciencias sociales en general---, pero también respecto de los modos de, en primer lugar, observar y analizar la realidad histórica y también social, pero en segundo lugar e íntimamente correlacionado con esto, de los modos de razonar y pensar sobre estas realidades, así como de las formas de explicar y explicarse las mismas. E igualmente, nos obliga a cambiar nuestra relación hacia los posibles resultados de este conocimiento social e histórico e incluso, quizá, también del mundo natural — conocimiento renovado por estas ampliaciones de los objetos y por estas transformaciones de los modos de acercamiento a la historia y a la sociedad, asumiendo también el cambio radical del estatuto general mismo que posee ahora ese conocimiento histórico social y en general. Expliquemos esto con más detalle.

A partir del rescate de los indicios, como fuente también esencial de la generación del conocimiento humano, va a ensancharse enormemente el objeto de estudio mismo de las ciencias sociales y de la historia en general, para quedarnos por ahora dentro de este universo de lo social-humano en el tiempo, y va a ensancharse de una doble manera.

Primero, porque a través de esos "espías" que son los "indicios", se nos abre el acceso a todo un conjunto de realidades que antes, y hasta hace muy poco tiempo, habían sido simple y llanamente ignoradas por la historia y por las ciencias sociales anteriores. Realidades ignoradas, a veces por su carácter huidizo o inaccesible, o por las dificultades que implicaba la escasez de testimonios, de fuentes, o de puntos de apoyo para su conocimiento, pero en otras ocasiones ignoradas también por ser realidades abiertamente despreciadas, marginadas, reprimidas y silenciadas por los poderes dominantes y por los discursos hegemónicos que les corresponden.

Realidades ocultas y marginales, que no eran ni visibles ni evidentes a primera vista y de modo inmediato, y a las que ahora nos es posible penetrar mediante esa estrategia epistemológica de la búsqueda y desciframiento de los indicios. Por ejemplo, la realidad de la cultura de las clases subalternas, cultura

\& El término italiano "spie" tiene ese doble significado que no se repite en otras lenguas, de espía, es decir de alguien que busca saber lo que oficialmente está prohibido conocer, pero también de "indicio" o pista que da acceso a una realidad de otro modo difícilmente accesible. 
que siendo durante siglos y milenios una cultura predominantemente oral, no ha dejado entonces como testimonio de su propia existencia y de sus características principales, otra cosa que diferentes ruinas -en el sentido benjaminiano de este último término"--, es decir, elementos sólo fragmentarios, incompletos y parciales, al modo de simples huellas o rastros, deformados, distorsionados, indirectos y sólo legibles con dificultad.

Una cultura subalterna que sólo puede ser captada de manera oblicua, y desde esos rastros o indicios que aún sobreviven de ella ${ }^{10}$, cuyo estudio y escudriñamiento minuciosos por parte de Carlo Ginzburg lo llevaron precisamente, entre otros caminos, hacia esta explicitación del paradigma indiciario. Porque recuperando en torno de este desciframiento y explicación de la cultura popular, las lecciones aprendidas de Leo Spitzer, Eric Auerbach, Theodor Adorno, Sigmund Freud o Marc Bloch, entre otros, Carlo Ginzburg ha logrado, mediante esos métodos spitzerianos y auerbachianos de la lectura intensiva de los textos, del adorniano desciframiento de los densos epigramas que condensan realidades ocultas y profundas, de la explicación freudiana de los síntomas y los signos reveladores, y de la blochiana interpretación de los contenidos que revelan involuntariamente los testimonios voluntarios e involuntarios, ha logrado reconstruir las estructuras principales constitutivas de la cultura campesina y de la cultura popular de Italia y de Europa en el singular "largo siglo XVI".

Porque allí donde el objeto que estudiamos se nos escapa de las manos por su fragilidad, y por su sobrevivencia solo ruinosa y fragmentaria -como en el caso de estas culturas de las clases subalternas-, allí se impone el uso de esta búsqueda de los indicios, los que como un mecanismo indirecto y alternativo, nos dan acceso a esas realidades de difícil captación y aprehensión.

Acceso a un vasto universo de temas y problemas históricos fundamentales, pero abandonados por esa dificultad intrínseca de su reconstrucción, que a partir de esta teorización y explicitación del paradigma indiciario se vuelven ahora accesibles

9 Sobre este punto, cfr. Walter Benjamin, Tesis sobre la bistoria y otros fragmentos, Ed. Contrahistorias, México, 2005, y Carlos Antonio Aguirre Rojas, "Walter Benjamin y las lecciones de la historia a contrapelo" en la revista UNAULA, num. 24, Medellín, 2004.

${ }^{10}$ Sobre este punto, vale la pena releer una vez más la brillante obra de Carlo Ginzburg El queso y los gusanos, Ed. Océano, México, 1998, y también nuestro ensayo, Carlos Antonio Aguirre Rojas, "El queso y los gusanos: un modelo de historia crítica para el análisis de las culturas de las clases subalternas" antes citado. 
al trabajo del historiador, ampliando con ello enormemente el campo u objeto general de los territorios que abarca la propia ciencia de la historia.

Pero también y en segundo lugar, el paradigma indiciario va a ensanchar el objeto de la ciencia histórica al superar un viejo y persistente debate inaugurado en el último tercio del siglo XIX, y que recorre casi todo el siglo XX cronológico: el debate entre, de un lado la postura del historicismo, y de otra parte, la postura de los defensores de la ciencia histórica como "ciencia de lo general", respecto de este mismo objeto de los estudios históricos. Pues frente a esta tenaz división, de quienes defienden que el objeto de la historia está constituido centralmente por los hechos y dimensiones ínicos, singulares e irrepetibles de los procesos humanos, en contra de quienes afirman que "sólo hay ciencia de lo general", y que el objeto de la historia son precisamente esos hechos comunes, generales y universales del hacer humano en el tiempo, frente a ambas posturas, el paradigma indiciario va a reivindicar en cambio la absoluta necesidad de abarcar ambas dimensiones, recuperando tanto las tendencias, procesos y elementos generales, como también e igualmente los hechos, dimensiones y caracteres específicamente individuales y singulares de la historia.

Porque si los indicios son espías que permiten el acceso a realidades ruinosas y de difícil aprehensión, también son herramientas privilegiadas que hacen posible la captación de la singularidad individual, específica e irrepetible, de cada "caso" histórico respecto de las correlativas normas o leyes de orden general que le corresponden. Ya que el indicio sólo adquiere sentido en tanto tal "indicio", si es capaz de revestirse de un significado revelador de estructuras profundas, y por lo tanto, de procesos y tendencias generales y universales, es decir, si se afirma como un cierto hecho que es sólo aparentemente secundario e intrascendente, pero realmente revelador de esas estructuras esenciales y profundas, para las miradas especialmente entrenadas en esa detección y explicación de dichos indicios.

Con lo cual, el paradigma indiciario pone en el centro de su atención esta compleja dialéctica entre norma, o ley, o tendencia, o proceso generales, y de otro lado el caso, o la realidad, o la manifestación, o la expresión específica y estrictamente individuales y singulares de dichas dimensiones generales. $Y$ con ello, no sólo supera simultáneamente los límites de la estrecha postura historicista, y las posibles malas interpretaciones y deformaciones de la postura 
"generalista" o "universalista", sino que también replantea en nuevos términos esa importante dialéctica entre lo general y lo particular dentro de la historia.

Pues si los indicios dan acceso a la singularidad irrepetible del caso, lo hacen sólo dentro de una lógica que considera a este caso investigado, como el caso de una norma, y por lo tanto, el elemento "revelador" de la específica totalidad de la que forma parte dicho caso. 0 como lo dice el propio Ginzburg: "si las pretensiones de conocimiento sistemático parecen cada vez más inconstantes, no por ello debe ser abandonada la idea de totalidad. Por el contrario: la existencia de una conexión profunda que explica los fenómenos superficiales es reafirmada en el momento mismo en que se sostiene que un conocimiento directo de tal conexión no es posible. Si la realidad es opaca, existen ciertos puntos privilegiados - señales, indicios - que nos permiten descifrarla". Para rematar: "Esta idea, que constituye el núcleo del paradigma indiciario o sintomatológico, se ha abierto camino en los ámbitos cognoscitivos más variados, modelando en profundidad a las ciencias humanas"

Ampliando así el objeto de la historia -y también de las ciencias sociales en general-, al incluir tanto a los elementos y dimensiones generales como a las realidades y hechos particulares del hacer humano-social, el paradigma indiciario nos permite dar cuenta del caso individual en su especificidad, pero también desde lo universal y como lección esencial para la construcción y definición de ese mismo universal. Lo que además de recuperar y dar sentido a la oportuna exigencia de Marx, de incorporar como uno de los niveles del análisis de la totalidad, también a este nivel del análisis de las dimensiones histórico-concretas de la realidad investigada, emparenta y vincula justamente a la historia con otras disciplinas de estudio de lo social, e incluso más allá, las

${ }^{11}$ Cfr. Carlo Ginzburg, "Huellas. Raíces de un paradigma indiciario", en el libro Tentativas, citado, Morelia, pp. 151152. Más recientemente, Ginzburg ha insistido en esta compleja relación entre normas y casos, y en este punto entre normas y casos amómalos, en su ensayo "Family Resemblances and Family Trees: Two Cognitive Methapors" en la revista Critical Inquiry, num. 30, Chicago, 2004, Pág. 556 (texto cuya versión en español se incluye en este mismo número de Contrabistorias), en donde afirma la mayor riqueza de partir de las anomalías para llegar a dichas normas. Y justamente, una de las virtudes del paradigma indiciario reside en permitir el acceso a ese caso -anómalo o no-- para a través de élllegar finalmente a la norma y a la totalidad, y con ello a esta dialéctica entre lo general y lo particular, tema por lo demás, igualmente central para todos los autores de la importante corriente de la microhistoria italiana. Sobre esta última, y sobre este problema mencionado, cfr. nuestro libro, Carlos Antonio Aguirre Rojas, Contribución a la bistoria de la microbistoria italiana, Ed. Prohistoria, Rosario, 2003 y también nuestro ensayo "Invitación a otra microhistoria: la microhistoria italiana", en la revista Histórica, vol. XXVII, num. 2. Perú, 2003. 
que cada vez asumen más conscientemente la tesis de que el buen juez extrae siempre lecciones generales de cada nuevo caso particular juzgado, así como el médico enriquece su visión general de una enfermedad con cada nuevo paciente individual tratado, mientras que el buen detective afina y perfecciona su conocimiento de los patrones criminales generales con cada nuevo crimen singular que resuelve, del mismo modo en que el buen historiador forma y desarrolla su concepción y su capacidad general de explicación de la historia, a partir de cada nuevo estudio de un suceso, un fenómeno o un proceso históricos investigados.

Porque si todos padecemos de gripe, cada cuerpo la vive y la sufre de un modo único y singular, igual que el hecho de que todos estamos sometidos a las leyes del inconsciente y de los complejos universales, pero cada uno de nosotros actualiza y escenifica esos complejos y esa vigencia del inconsciente de un modo completamente personal e irrepetible. Y es justo a través del desciframiento de los indicios que se restituyen, tanto esa singularidad particular del caso individual, como también esa obvia e ineludible presencia y manifestación de la norma o del patrón general y universal dentro del caso en cuestión.

De este modo, la explicitación del paradigma indiciario ensancha las fronteras del objeto de la ciencia histórica en un doble sentido: primero, al darnos acceso a toda una serie de realidades de difícil aprehensión, por haber sido marginadas, reprimidas o silenciadas, o por haber sobrevivido sólo en estado de ruinas y fragmentos, y segundo, al incluir por igual las dimensiones tanto generales como particulares de los procesos históricos, replanteándolas y concibiéndolas de un modo novedoso y original, pero también superador de las viejas visiones basadas en antinomias simplistas y excluyentes ${ }^{12}$. Visión más

12 En este sentido, el paradigma indiciario se inscribe en toda la tradición de la historiografía y de las ciencias sociales genuinamente críticas, las que desde Marx y hasta hoy, han tratado también por muy diversas vías de superar y dialectizar estas falsas antinomias rígidas y simplistas, que oponen por ejemplo al individuo y a la sociedad, al personaje y al contexto, al actor social y a las estructuras, a la macrohistoria con la microhistoria, a lo global con lo local, a lo material con lo espiritual, a lo económico con lo cultural, y un largo etcétera posible. Pero autores tan brillantes como el propio Marx, o Walter Benjamin, o Norbert Elias, o Marc Bloch, o Fernand Braudel, han criticado y superado siempre estas visiones dicotómicas rígidas, falsas y esquemáticas. Al respecto y sólo para el ámbito de la historia, cfr. nuestros libros, Carlos Antonio Aguirre Rojas, Antimanual del mal bistoriador, 8 a . edición, Ed. Contrahistorias, México, 2005, Corrientes, Temas y Autores de la bistoriografía contemporánea, Ed. Universidad Juárez Autónoma de Tabasco, Villahermosa, 2002, La bistoriografía en el siglo XX, Ed. Montesinos, Barcelona, 2004, y Retratos para la Historía, Ed. Contrahistorias, México, 2006, ya antes mencionado. 
amplia y más adecuada de los objetos a estudiar por parte de la disciplina histórica, que se corresponde además con una clara asunción del verdadero estatuto del conocimiento histórico, y hasta del conocimiento de lo social en general, asunción que abre e inaugura el reto de la futura edificación global de un nuevo paradigma epistemológico general, exchusivamente característico de todo este conjunto de las ciencias sociales consideradas en su totalidad.

4. Los vastos alcances generales y el valor universal del paradigma indiciario, se revelan también cuando asumimos que el mismo representa una clara y radical "toma de conciencia" del específico estatuto epistemológico que poseen las ciencias humanas o sociales en general, como un estatuto que es, de modo necesario, algo radicalmente diferente al estatuto cognoscitivo de las ciencias naturales. Porque si todavía en el siglo XIX, e incluso durante un buen segmento del siglo XX, la historia vivió bajo la ilusión de compartir el mismo paradigma de cientificidad que las ciencias naturales, eso la llevó siempre a callejones sin salida, que la conducían a la alternativa de elección entre construir verdades exactas pero irrelevantes, o en el otro extremo la de establecer verdades cualitativas y profundas pero sólo conjeturales, inciertas y aproximativas. Y todo ello, por tratar de imitar, fallidamente, un paradigma galileano que es esencialmente cuantificante, generalizador y abstracto, y que sacrificaba y marginaba a lo cualitativo, a lo individual y a lo concreto de los específicos fenómenos estudiados.

Pero si, como nos lo recordó Marx, siguiendo a Vico, "la historia de la humanidad se diferencia de la historia natural en que la primera la hemos hecho nosotros y la otra no"13, entonces es claro que el paradigma epistemológico general de una y otra historia no puede ser el mismo, y por lo tanto, esa historia de la humanidad, y con ello las distintas ciencias sociales que la estudian, deberán construir su singular y exclusivo paradigma epistemológico, diverso del paradigma que intenta aprehender al mundo de la naturaleza, y sólo correspondiente a esta indagación de la obra de los hombres en el tiempo.

13 Cfr. Carlos Marx, El Capital, Tomo I, vol. 2, pág.. 453, nota 89, donde Marx plantea que, hasta ese momento en que él escribe, no existe todavía dentro de este campo de las ciencias sociales humanas, un trabajo equivalente al que Carlos Darwin realizó para el campo de las ciencias naturales. Ausencia que precisamente ha intentado colmar, el complejo aunque lamentablemente no totalmente completado proyecto crítico del propio Carlos Marx. 
Ya que en el vasto campo de ese hacer humano en el tiempo, que es el objeto de todas las llamadas ciencias sociales, aparecen factores que no están presentes en el mundo de la naturaleza, como la libertad humana, y la voluntad y la conciencia de los hombres, junto a la intencionalidad y la creatividad del género humano, entre otros elementos, lo que genera una realidad que, para ser explicada, requiere de otras y muy' diferentes estrategias cognoscitivas a las que empleamos para aprehender y explicar el mundo natural. Estrategias cognoscitivas divergentes de las utilizadas por las ciencias naturales, entre las que se incluye sin duda la estrategia del paradigma indiciario.

Porque al introducir dentro de la realidad de lo social todos esos elementos derivados de la presencia e influencia de lo humano, no sólo construimos un nivel de fenómenos de una mayor complejidad que el de los fenómenos del mundo natural, sino también todo un universo de elementos que funcionan con otra lógica, otro sentido y otros modos de funcionamiento distintos a los puramente naturales. Lo que entonces, complica y limita la aplicación del paradigma galileano para el estudio de estas realidades sociales, al mostrar como demasiado estrechos a la cuantificación rigurosa, la matematización del mundo, la generalización permanente y la constante reducción de lo concreto a lo abstracto, propias de este modelo de cientificidad. Estrechez de esta estrategia y modelo galileanos, frente a la cual se legitima y reivindica el paradigma indiciario, mucho más elástico y flexible, y por ende, más capaz de captar lo cualitativo, lo individual, lo concreto y lo singular, si bien desde una estrategia que aún hoy está menos formalizada, establecida y precisa que aquella delineada por Galileo hace aproximadamente medio milenio.

Y si las ciencias sociales son profundamente distintas de las ciencias naturales, no sólo porque en las primeras el sujeto que conoce coincide con el objeto a conocer -siendo en ambos casos, como es obvio, la humanidad misma-, sino también porque, como bien lo ha señalado Marc Bloch, en el campo de las ciencias sociales la experimentación, entendida como la reproducción consciente, voluntaria y regulada del fenómeno estudiado, simplemente no existe ${ }^{14}$. Lo que implica que tanto la verificación como la

14 Cfr. Marc Bloch, Apología para la Historia o el Oficio de Historiador, Ed. Fondo de Cultura Económica, México, 1996, págs. 129-132 y 159-168, que contienen muy agudas reflexiones sobre este estatuto específico del conocimiento histórico, pero también con relativizaciones importantes del supuesto conocimiento 'exacto' de las ciencias naturales y de la imagen general acerca de estas, ideas que recientemente han venido a ser confirmadas tanto por la teoría del caos como también por las llamadas ciencias de la complejidad, punto que veremos un poco más adelante. 
prueba sean muy diferentes a las de las ciencias naturales, pero también que el tipo de verdades que elaboran estas ciencias sociales sea cualitativamente distinto de las verdades sobre el mundo natural o sobre el universo hasta ahora conocido.

Conocimiento de lo social que alude a una realidad que no es reproducible de manera experimental, y que en la mayoría de los casos sólo se conoce por vías "indirectas", que en consecuencia tendrá que apoyarse para su construcción, en distintos tipos de testimonios y fuentes, pero también y reiteradamente en la búsqueda y el desciframiento de todo tipo de huellas, vestigios, rastros, signos, señales, síntomas o indicios.

Pero si este conocimiento de lo social es radicalmente diverso del conocimiento de lo natural, y si utiliza otras lógicas y otras estrategias cognoscitivas, siendo además un conocimiento no experimental y muchas veces indirecto y apoyado en los indicios, entonces es comprensible que también sea distinto su principal resultado intelectual, es decir el tipo de verdad que él mismo genera. Pues las verdades que se establecen en el ámbito de lo social no serán verdades exactas, rigurosas, comprobables y precisamente mensurables, sino más bien verdades conjeturales, aproximativas, hipotéticas y más bien cualitativas, aunque igualmente serias, razonadas y fundamentadas. Porque en su inmensa mayoría, los "hechos duros" de la historia -y también de la economía, la sociología, la psicología, etcétera-, que son hechos ciertos y comprobables, son generalmente los hechos más superficiales y menos importantes, mientras que las estructuras profundas y los procesos esenciales de esa misma historia y de esas distintas realidades sociales, son los que sólo podemos conocer de ese modo vinculado más que a lo cierto y a lo exacto, a lo "infinitamente probable" o enormemente verosímil.

Flexibilizando así la noción misma de verdad, para abrir el abanico de su definición, y abarcar en esta última la gradación que va desde lo cierto hacia lo verdadero, de este último hacia lo verosímil, y luego hacia lo probable y hasta lo simplemente posible, entre otros varios, el paradigma indiciario cambia también totalmente la noción, el rol y el estatuto de la prueba en la historia y en las ciencias sociales, al mismo tiempo en que incorpora, junto a la deducción y la inducción, a la abducción de Charles Peirce, legitimando el 
razonamiento probabilístico y la comparación analógica dentro de las actuales vías de construcción de las ciencias sociales más contemporáneass ${ }^{15}$.

"Elías Contreras, como la mayoría de los zapatistas, era un cazador. Y como tal sabía huellar' al animal. Es decir, sabía seguirle el rastro. El rastro, la huella, el vestigio, la pista. Entre el cazador y el detective hay este hilo común".

Subcomandante Insurgente Marcos, "En memoria de Bertold Brecht", 5 de junio de 2006.

5. A tono con esta "explosión" y dilatación del objeto de la ciencia histórica, y esta reivindicación del estatuto singular del conocimiento sobre lo social humano en la historia, y de la concomitante transformación de las nociones de verdad, de prueba y del modo de la inferencia cognoscitiva en juego, van a ensancharse y a trastocarse también, tanto las jerarquías particulares como las clasificaciones específicas y hasta los límites determinados de los modos del saber hoy todavía vigentes. Pues dado el estatuto no experimental y muchas veces indirecto y conjetural del conocimiento de lo histórico y de lo social, y dados también los problemas a resolver por este paradigma indiciario, de esas realidades difícilmente aprehensibles y de esos casos individuales en su conexión singular con la ley o norma general, va a replantearse nuevamente el problema de los límites específicos de los modos del saber burguésmoderno, hoy todavía ampliamente extendido y aún dominante.

Saber burgués característico de la modernidad, condensado ejemplarmente en el paradigma galileano de la cientificidad, cuyos rasgos principales son la reivindicación de los procesos racionales formalizables, que

\footnotetext{
15 Por eso, no es una casualidad que una de las vías que ha sido recorrida por Carlo Ginzburg en los años posteriores a la publicación de este texto de "Indicios", sea precisamente esta de la tematización del estatuto de la verdad, de la prueba, de las formas de control de los resultados, y de los procedimientos oblicuos de lectura de los testimonios dentro de la ciencia histórica. Al respecto cfr. los libros Tentativas, citado antes, y en especial los capítulos 5, 7 y 10; Rapporti di forza, Ed. Feltrinelli, Milán, 2000, especialmente la introducción y los capítulos 1 y 2, y el libro Il filo e le tracce. Vero, falso, finto, Ed. Feltrinelli, Milán, 2006.
} 
llevan a cabo operaciones lógicas como la inducción y la deducción, y que apoyados tanto en el conocimiento libresco y en el trabajo del cerebro, como también en el experimento y en la comprobación práctica y empírica, establecen verdades ciertas, exactas, rigurosas y tendencialmente mensurables de modo cada vez más preciso. In saber que, en consecuencia, no es capaz de abarcar ni de comprender otros modos diversos del saber y del conocer, tan ricos, variados y complejos como el saber del buen catador de vino, o el del conocedor de la obra de arte, o el del fino y agudo psicoanalista, o el buen médico, pero tampoco el del verdadero líder popular, el del buen carpintero o marinero, el del detective experto, o el del historiador realmente capaz de descubrir y de descifrar los distintos "indicios" del tema de historia que investiga.

Límites e incapacidad de aprehensión de este saber moderno-burgués, que serán evidenciados por el paradigma indiciario, el que si bien utiliza igualmente ciertos mecanismos de ese mismo saber moderno dominante, no descarta sin embargo a esos otros modos generadores del saber que son la abducción, el razonamiento probabilístico, el razonamiento fulmineo, el descubrimiento intelectual de raíces aún inexplicadas, pero incluso también el golpe de vista, la corazonada o hasta la intuición (estos últimos, mecanismos que aún no sabemos explicar racionalmente, pero que muy posiblemente se vinculan con la memoria y el razonamiento instantáneos, con un conocimiento semiconsciente que aflora de pronto, o con certezas o verdades latentes que emergen de pronto y en ciertas circunstancias dadas).

Yello, no para reivindicar un absurdo y ridículo nuevo irracionalismo moderno, como hacen todas las posiciones del postmodernismo en la historia y en las ciencias sociales, sino más bien para poner en cuestión y asumir con todas sus consecuencias, esos límites cada vez más obvios y cada vez más paralizantes de ese saber burgués dominante, que hoy está en su clara etapa de crisis terminal y definitiva ${ }^{16}$.

\footnotetext{
${ }^{16}$ Una crisis múltiple de todas las estructuras del saber moderno-burgués, que se manifiesta lo mismo en el ámbito de las ciencias naturales, con el surgimiento de la teoría del caos y de las ciencias de la complejidad, que en el ámbito de las humanidades y de las artes, lo mismo que en todo el territorio de las modernas ciencias sociales. Sobre este punto, al que volveremos más adelante, cfr. Ilya Prigogine e Isabelle Stengers, La nueva alianza, Ed. Alianza Editorial, Madrid, 1997, y también Illya Prigogine, El fin de las certidumbres, Ed. Andrés Bello, Santiago de Chile, 1996 y Las leyes del caos, Ed. Crítica, Barcelona, 1997; Wolf Lepenies, Las tres culturas, Ed. Fondo de Cultura Económica, México, 1994, e Immanuel Wallerstein, Abrir las ciencias sociales, Ed. Siglo XXI, México, 1996, Impensar las ciencias sociales, Ed. Siglo XXI, México, 1998, Conocer el mundo, saber el mundo, Ed. Siglo XXI, México, 2001, y también Las incertidumbres del saber, Ed. Gedisa, Barcelona, 2005.
} 
Crisis y límites que se manifiestan hoy agudamente, en el ámbito de las ciencias naturales, como la crítica radical y la superación teórica frente a los modelos rígidos y simplistas basados en la afirmación de un determinismo lineal y predecible, y en una reversibilidad que ignora olímpicamente los efectos de la flecha del tiempo, a la vez que concibe a los sistemas siempre como sistemas en condiciones de equilibrio, y que persigue la mayor precisión cuantitativa de sus posibles resultados. Lo que, en el ámbito de las ciencias sociales, se reproduce como la crítica a las estructuras "disciplinares" de este mismo conocimiento de lo social, y a las falsas y fallidas propuestas totalmente erróneas aunque hoy muy de moda, de la interdisciplinariedad, multidisciplinariedad, pluridisciplinariedad o transdisciplinariedad. Lo que, también a su manera, se repite igualmente en el ámbito de las humanidades y las artes, como crítica de su artificial e infundada separación de las ciencias sociales, y como exigencia de historización y explicación crítica de los distintos cánones de lo bello y de lo artístico, a lo largo de los tiempos de la historia humana ${ }^{17}$.

Crisis entonces global de los saberes burgueses y modernos hoy dominantes, que no sólo legitima la validez y pertinencia de la reivindicación del paradigma indiciario, sino también y más allá de este último, nos abre a la revaloración y al rescate de todos aquellos saberes y estrategias cognoscitivas que la modernidad burguesa despreció y marginó durante cinco siglos, y que hoy retornan nuevamente como saberes y estrategias igualmente legítimas, e igualmente rescatables y fructíferas para la aprehensión más fina, completa y orgánica de nuestras múltiples realidades y de nuestros diversos mundos y universos.

\footnotetext{
${ }^{17}$ Las manifestaciones de estos límites del moderno saber burgués son cada vez más diversas y evidentes: por ejemplo, es claro que la racionalidad burguesa, totalmente adialéctica, no puede aún resolver hoy en términos de su propia ciencia lógica las paradojas de Zenón de Elea, sobre cómo es posible recorrer un número infinito de puntos en un tiempo finito. Pero igual no tiene solución a la pregunta de si Dios, que supuestamente es todopoderoso, podría entonces crear una piedra tan pesada que ni él mismo fuese capaz de levantarla. Y también estos límites se hacen evidentes en la empobrecida concepción burguesa moderna del tiempo, que sigue aún pensándolo bajo la estrecha tripartición de pasado/presente/futuro, criticada mil veces por los más distintos analistas de todo el siglo XX. Y es claro que sólo un pensamiento genuinamente crítico y genuinamente dialéctico, y por lo tanto forzosamente trascendente del saber moderno burgués, puede superar estos límites y resolver estos impasses de ese mismo saber burgués hoy todavía dominante. A este respecto, y a título de simples llustraciones de estos límites, cfr. Norbert Elías, Sobre el tiempo, Ed. Fondo de Cultura Económica, Madrid, 1989, Carlos Antonio Aguirre Rojas, "La larga duración: in illo tempore et nunc", en el libro Ensayos braudelianos, Ed. Prohistoria, Rosario, 2000, y también la breve nota titulada "Aprendiendo a pensar" incluida en la revista Memoria, num. 161, México, pág. 62, en donde se narra una muy curiosa pero interesante anécdota de Niels Bohr y de Emest Rutherford.
} 
Yen primer lugar, la reivindicación del saber y de la cultura populares, los que cada vez más son reconocidos como saberes y culturas que son diferentes pero no inferiores a la cultura y al saber dominantes, siendo estudiados y revalorados para descubrir su carácter dinámico, innovador, creativo y constantemente generador de nuevas formas y contenidos, a partir de su vínculo privilegiado con el mundo de la experiencia, y de su condición como cultura y saber originales y originarios de toda otra posible cultura y de todo otro posible saber.

Y si bien es claro que el paradigma indiciario no es un elemento o un patrimonio exchusivo de las culturas subalternas o de los saberes populares, pues igualmente ha sido y puede ser reapropiado por las clases dominantes y por los saberes hegemónicos, también es claro que dichas clases y culturas subalternas se encuentran más cercanos de ese saber a través de indicios, que las clases dominantes. Porque mientras que las clases sometidas y explotadas aprehenden siempre el mundo desde la base de sus experiencias directas, y por tanto asimilan pronto y directamente este saber indiciario de los cazadores, los marineros, los carpinteros o los verdaderos líderes populares, entre otros, las clases dominantes en cambio, que aprehenden el mundo muchas veces desde un conocimiento libresco, y bajo los marcos estrechos del paradigma de cientificidad, primero platónico, y luego galileano, tienen en cambio que desaprender parte de lo aprendido, y abrirse más allá de sus propios límites, para ser capaces de asimilar y practicar dicho paradigma indiciario. Lo que, lógicamente, explica en nuestra opinión, el hecho de que haya sido Carlo Ginzburg, estudioso asiduo y puntilloso de dichas culturas y saberes populares, respecto de las cuales manifiesta una clara y abierta simpatía, el que logró teorizar y explicitar este mismo paradigma epistemológico de la lectura y desciframiento de los indicios.

6. ¿Existe realmente el famoso "espíritu de la época", el Zeitgeist reivindicado por los autores alemanes?. Quizá si o quizá no, pero lo que sin duda si existe, son contextos culturales específicos de cada coyuntura histórica, que plantean problemas similares a los distintos investigadores y científicos de todo orden que trabajan dentro de estos contextos y estas coyunturas determinadas. Lo que, naturalmente, provoca que autores e investigadores situados en países diferentes, y en disciplinas y campos de estudio también 
diversos, lleguen a proponer en ocasiones tesis y planteamientos coincidentes, o convergentes, o simplemente cercanos y similares.

Y no es para nada una casualidad el hecho de que el paradigma indiciario haya sido teorizado y explicitado en 1978-79, es decir en la coyuntura cultural y social que se creó a nivel mundial, como resultado de las múltiples revoluciones culturales simbolizadas en el emblemático año de 1968, pero también y más en general, en la coyuntura social global posterior a 1972-73, que abre el periodo de la crisis terminal y definitiva del actual sistema capitalista mundial. Coyuntura múltiple y global, que junto a la crisis civilizatoria que todavía hoy padecemos en todo el planeta -y que se expresa lo mismo en la catástrofe ecológica hacia la que lentamente caminamos, junto a la crisis económica indetenible que se hace evidente, por ejemplo, en el florecimiento ilimitado y mundial de las economías "subterráneas", o "informales", o "ilegales" o "paralelas", al lado de la crisis social que exuda una nueva violencia social incontrolada, y a la debacle de todos los Estados y de todo el nivel de la política y de lo político modernos, entre otros síntomas - va a manifestarse también en el plano cultural como crisis global de la entera configuración de la racionalidad burguesa moderna, y con ello, de todo el conjunto de sus principales estructuras de saber.

Por eso, no es fortuita la coincidencia temporal del desarrollo de la propuesta del paradigma indiciario, y su crítica frontal al paradigma galileano, con el nacimiento de la teoría del caos y el desarrollo de los estudios de las ciencias de la complejidad, paralelamente al desarrollo de la perspectiva desarrollada por Immanuel Wallerstein del "análisis de los sistemas-mundo" y su propuesta de "impensar las ciencias sociales actuales", o a la afirmación y difusión de la corriente historiográfica de la microhistoria italiana, lo mismo que a la popularización y enorme difusión de los trabajos de autores anteriores como Norbert Elías o Walter Benjamin, entre otros.

Coincidencia no sólo temporal sino de ciertas preguntas y de ciertas respuestas, que más allá del hecho de que en todos estos casos citados se trata de distintos acosos críticos a las formas de la racionalidad burguesa imperante, y también de la búsqueda de otros modos de pensar y razonar, modos realmente alternativos a esa racionalidad burguesa, se prolonga incluso en la similitud de ciertas tesis y análisis más específicos y particulares. Por ejemplo, en el 
énfasis que este paradigma indiciario asume respecto de la gran relevancia que poseen los aspectos cualitativos e irreductiblemente individuales de los hechos históricos o sociales investigados, énfasis que estando presente también en toda la corriente de la microhistoria italiana - a la que el propio Carlo Ginzburg pertenece--, nos conecta igualmente con la crítica que los estudios complejos realizan al objetivo reiterado de las ciencias naturales, de lograr siempre la mayor precisión cuantitativa posible en la explicación y reproducción intelectual de la realidad estudiada.

Pero ya Mandelbrot ha demostrado que no existe una sola representación exacta y rigurosa de la Costa de Bretaña, porque los mapas posibles de esa Costa son infinitos, y varían según la escala elegida de su construcción. Entonces ¿cuál es el mapa más exacto y riguroso de la Costa de Bretaña?, es una pregunta que no tiene respuesta, e incluso ni siquiera la del mapa que, como en el cuento de Jorge Luis Borges, mediría exactamente lo mismo que la propia realidad geográfica que intenta reproducir, pues esta última cambia todo el tiempo por la erosión, las mareas, el desgaste terrestre, etcétera ${ }^{18}$. Con lo cual ese objetivo de la mayor precisión cuantitativa y el máximo rigor medible se desvanece, para ceder su lugar a reproducciones más cualitativas y aproximativas, pero también más individualizadas y específicas, en tanto que conscientes de la escala elegida en función de los objetivos cualitativos de la representación o reproducción escogida.

Y junto a esta convergencia en dicho énfasis sobre la importancia de lo individual y lo cualitativo, que sin embargo no olvida ni suprime al nivel general y a la dimensión cuantitativa, estaría la reivindicación del necesario grado de incerticumbre ineliminable que poseen las verdades históricas y también muchas verdades sociales. Incertidumbre que da fundamento y legitimidad al razonamiento conjetural y a la abducción, y que reaparece también en la concepción global de la teoría del caos, la que entre sus postulados centrales afirma que, en la vasta inmensidad del universo, lo que predomina

\footnotetext{
${ }^{18}$ Sobre este punto cfr. Benoit Nandelbrot The fractal geometry of nature, Ed. W. H. Freeman, Nueva York, 1983, y también Bernard Lepetit "Architecture, Geógraphie, Histoire: Usages de l'echelle" en la revista Gèneses, num. 13, 1993, Immanuel Wallerstein "The challenge of maturity. Weather social science?" en Reriele, vol. 15, num. 1, Binghamton, 1992, y Carlos Antonio Aguirre Rojas "Una perspectiva global del análisis de los sistemas-mundo" en el libro Immanuel Wallerstein: Crítica del sistema-mundo capitalista, Ed. Erá, México (2a edición), 2004, pp. 111-135.
} 
mayoritariamente no son los sistemas en situación de equilibrio, sino por el contrario, los sistemas en situación de bifurcación.

Lo que, además de romper con la creencia sostenida durante cinco siglos por el modelo baconiano-newtoniano de la ciencia, introduce entonces el carácter ampliamente vigente del elemento estocástico dentro del estudio y explicación de dicho universo, y con ello, no sólo el "fin de las certidumbres" antes adquiridas, sino también el reconocimiento del carácter parcial, fragmentario, acotado y también incierto de las verdades hasta hoy obtenidas dentro de las ciencias naturales, también llamadas, lo que hoy parece una cierta ironía, "ciencias exactas".

Pero si esas verdades de las ciencias naturales se encuentran también sometidas a la vigencia de la flecha del tiempo, y circunscritas a esos espacios restringidos del universo que son los sistemas en equilibrio, entonces el paradigma indiciario que alude a realidades difícilmente accesibles y de comportamientos y trayectorias inciertas, quizá también tiene algo que aportar en el desciframiento y análisis todavía en curso de esa otra vasta parte del universo que no está en equilibrio, sino más bien en condiciones de constante bifurcación, y de un caos gobernado por ciertas leyes - a pesar del carácter paradójico de esta última afirmación-.

E igualmente resulta interesante la coincidencia entre la tesis del paradigma indiciario, que reivindica la necesidad de vincular siempre el caso con la norma, y por esta vía el nivel microhistórico con el nivel macrohistórico - tema también central de todo el enfoque de la microhistoria italiana-, buscando los modos complejos de su articulación, de su dialéctica y de su síntesis, con el similar esfuerzo que plantea Ilya Prigogine en su teoría del caos, de buscar también las conexiones, los juegos recíprocos y las interacciones diversas entre las realidades macroscópicas de nuestro mundo cotidiano, teorizado y explicado por Newton, y de otra parte las realidades microscópicas estudiadas por la mecánica cuántica y por la física de los átomos. Pero también y en sentido inverso, los múltiples vínculos y la dialéctica específica entre nuestro newtoniano universo mejor conocido, aquí considerado como un nivel microscópico, y el más vasto y lejano universo de las estrellas, los hoyos negros y las diversas realidades cósmico-globales, las que en esta nueva articulación funcionan como el nivel macroscópico. 
Un movimiento a través de distintas escalas del universo, que no sólo revela los límites de nuestras capacidades bumanas de observación y de análisis, y por ende el carácter todavía incipiente, inicial y provisional de todos nuestros conocimientos sobre el mundo natural y sobre el universo -otro claro punto de coincidencia con el paradigma indiciario y con la perspectiva de la microhistoria italiana, en este caso en lo que se refiere a dicha fragilidad, incertidumbre y provisionalidad de nuestros conocimientos de la historia y de la sociedad-, sino que hace evidente, una vez más, el todavía muy largo camino que nos falta recorrer para alcanzar una más adecuada y certera comprehensión del universo y de la naturaleza, pero también de la historia humana y de sus múltiples sociedades desplegadas a lo largo del tiempo.

Pues igual que una mirada macroscópica, que ve mezclarse una gota de tinta con otra gota de agua, cree percibir que el agua se ha vuelto gris, mientras que un análisis microscópico revela que las moléculas del agua y de la tinta solamente se han fragmentado y dispersado para combinarse, pero sin mezclarse realmente, así un estudio microscópico y apoyado en la aplicación del paradigma indiciario, es capaz de revelar realidades y verdades históricas imperceptibles desde el sólo nivel macrohistórico tradicional ${ }^{19}$.

Así, creemos que es por estas coincidencias señaladas, y por otras que aquí no hemos desarrollado, por las cuales Carlo Ginzburg tiene la impresión, desde el momento mismo de la primera edición del ensayo de "Indicios", de estar publicando un "ensayo que no dice cosas demasiado nuevas", o también de haber expresado algo "que estaba ya en la atmósfera de ese momento", "dando voz a temas difusos que se mantenían en estado latente". Pues dicha atmósfera de la época no es otra que la de la crisis terminal, definitiva e irreversible de la limitada racionalidad burguesa moderna, junto a todos los saberes y a todas las ciencias que ella ha engendrado, crisis que se expresa en las múltiples respuestas e intentos de salida a ella que son, lo mismo la teoría del caos que la microhistoria italiana, los estudios complejos igual que la perspectiva del análisis de los sistemas-mundo, las obras de la

\footnotetext{
${ }^{19}$ Sobre este punto, cfr. Carlo Ginzburg, "Microhistoria: dos o tres cosas que sé de ella", en la revista Ruptura, num. 10-11, Villahermosa, 2002, y también "Details, gros plans, microanalyse. Reflexions sur un livre de Sigfried Kracauer", en la revista electrónica Theomai, num. 11, abril de 2005, en el sitio: http:// www.unq.edu.ar/revista-theomai.htm, y también Carlos Antonio Aguirre Rojas, "Invitación a otra microhistoria: la microhistoria italiana" en la revista Histórica, antes citado.
} 
más radical y más crítica historiografía marxista británica o también en la tesis del paradigma indiciario que ahora comentamos.

Paradigma indiciario que, lejos de ser "una banalidad", constituye más bien una pequeña revolución epistemológica, equiparable a la que significó en su momento el artículo sobre la larga duración histórica de Fernand Braude $^{20}$. Pequeña revolución epistemológica que, con este aporte del paradigma indiciario, enriquece y ensancha de manera importante nuestras posibilidades generales de aprehensión y de conocimiento de la historia y de lo social-humano, al hacer explícito y al teorizar todo un nuevo modo de conocimiento de lo histórico-social -y quizá más allá-, toda una nueva estrategia epistemológico-cognoscitiva que se suma al acervo importante de las nuevas formas de la racionalidad que, en un futuro no muy lejano, deberán de sustituir a las estructuras de saber y a las ciencias burguesas modernas hoy todavía dominantes, formas nuevas de la racionalidad que hoy se encuentran en proceso de construcción y afirmación definitivas.

7. Al mismo tiempo en que este importante ensayo de "Indicios" se ha ido difundiendo en escala planetaria, y ha ido afirmándose como uno de los textos hoy ya "clásicos" de la metodología histórica y de la metodología de las ciencias sociales, se han comenzado a desarrollar también múltiples malas interpretaciones de sus principales tesis, junto a claras simplificaciones de sus propuestas centrales, pero también al lado de extrañas exageraciones de su alcance y de sus posibilidades cognoscitivas específicas.

Pues de la misma manera que muchas de las tesis centrales del marxismo original, o también del ensayo braudeliano sobre "la larga duración", así también este texto sobre los "Indicios" ha sido objeto de las más diversas lecturas y análisis, y con ello de dichas deformaciones, simplificaciones y extrañas y desmesuradas interpretaciones. Por ejemplo, la idea de que absolutamente todos los hechos históricos constituyen "indicios" en un sentido estricto, o

\footnotetext{
${ }^{20}$ Y no está demás agregar que, del mismo modo en que el célebre ensayo braudeliano constituye una clave esencial para comprender la entera obra del gran autor de El Mediterráneo y el mundo mediterráneo en la época de Felipe II, y también de Civilización material, economía y capitalismo, así también este ensayo de "Indicios", es una clave fundamental para entender la entera obra de Carlo Ginzburg hasta hoy concretada.
} 
también la ilusión de que el paradigma indiciario constituye un método universal de conocimiento de absolutamente todas las realidades históricas, e incluso sociales, y tal vez hasta naturales y cósmicas, es decir que es una especie de llave que abre todas las puertas de absolutamente todos los problemas que aborda el conocimiento humano.

Pero igualmente, la idea de que el paradigma indiciario es necesariamente subversivo en sí mismo, y que los "indicios" son fatal y obligadamente revolucionarios. Aunque, y en el otro extremo, también la peregrina tesis de que la perspectiva de Carlo Ginzburg sería una de las tantas expresiones de la historiografía postmoderna, y con ello, que este texto de "Indicios" sería una crítica radical al paradigma de cientificidad moderno, y por ende, una defensa de los puntos de vista postmodernos dentro de la historiografía. 0 también, la afirmación de que estos "Indicios" se vinculan exclusivamente y de modo forzoso con la historia de los marginados, o con el universo de la cultura popular o de las culturas subalternas. Y ello, entre muchas otras raras y a veces difícilmente imaginables explicaciones o visiones sobre estos "indicios" y este paradigma indiciario ${ }^{21}$.

Toda una serie de malas interpretaciones o deformaciones de las tesis del paradigma indiciario que, en nuestra opinión, se explican sin duda a partir de la novedad y de la complejidad intrínsecas de este ensayo -suerte de palimpsesto que, para argumentar y explicitar sus hipótesis centrales, recorre un arco temporal que abarca a toda la historia del hombre, y a una enorme variedad de casos que cubren las más variadas formas del conocer humano en la historia - pero también, y de modo importante, a partir del hecho de que en tanto que formulación y teorización de toda una estrategia cognoscitiva humana, que es explicitada de manera orgánica por primera vez en la historia,

${ }^{21}$ Sobre estas varias y muy diversas interpretaciones del paradigma indiciario, entre las que se incluyen todos los ejemplos recién mencionados, cfr. los ensayos de Andrea Carandini y Mario Vegetti, incluidos en Quaderni di Storia, num. 11, 1980, de Mario Vegetti, Gianni Vatimo y Pierre Aldo Rovatti, en la revistaAut-Aut, num. 175, 1980, la transcripción del debate sobre el paradigma indiciario - donde participa el propio Carlo Ginzburg, junto a nueve otros autores-, en Quaderni di Storia, num. 12, 1980, los ensayos de Albino Cánfora, y otro ensayo colectivo, en Quaderni di Storia, num. 14, 1981, y el ensayo de Melti Peltonen "Indicios, márgenes, mónadas. Acerca del advenimiento de la 'nueva microhistoria"', en el libro Ensayos sobre microbistoria, antes citado. A varias de estas malas interpretaciones ha aludido el mismo Ginzburg en su texto "Intervención sobre el paradigma indiciario", incluido también en este mismo número de Contrabistorias. 
imbrica varios niveles y varias posibles definiciones, que es necesario distinguir y separar claramente, para ser capaces de comprender mejor y más adecuadamente a este mismo paradigma indiciario.

Niveles y definiciones que, en una primera aproximación más detenida y puntual, deberían diferenciar entre, primero, el reconocimiento y desciframiento riguroso de los indicios, es decir la definición de los indicios en su sentido estricto; en segundo término, la posible lectura indiciaria de hechos que por sí mismos no son indicios, o la definición de una suerte de indicios en sentido amplio o laxo, y en tercer lugar, la asunción y configuración explícita de una estrategia indiciaria de conocimiento de la realidad, o la definición precisa del paradigma indiciario en general. Veamos esto con más detalle.

8. Si releemos con cuidado el ensayo de "Indicios", veremos que en todos los casos que Carlo Ginzburg refiere como ejemplo de conformación o de aplicación del paradigma indiciario, se repiten ciertos trazos o elementos que, en su conjunto, nos permiten intentar una definición más puntual de lo que son dichos "Indicios", concebidos en su sentido más estricto y riguroso. Definición que siendo aplicable a todas esas estrategias cognoscitivas puestas en acción por los cazadores, los adivinadores, los médicos, los carpinteros, los jueces, los marineros, los políticos, los alfareros, los críticos pictóricos, los psicoanalistas o los detectives, pero también por los historiadores, nos aclara algunas de las más recurrentes y erróneas interpretaciones de este mismo paradigma basado en el desciframiento de los indicios.

Así, un indicio en sentido estricto es una huella, o rastro, o síntoma, o trazo, o vestigio, o señal, o signo, o elemento, que siendo el resultado involuntario, o del despliegue y existencia de un cierto proceso o de una cierta realidad, o a veces de una creación inconsciente de su propio autor, se constituye en un dato que sólo aparentemente es marginal o intrascendente, pero que analizado con más cuidado, se muestra como un dato revelador de una realidad oculta, más profunda y esencial, realidad que no siendo accesible de un modo directo y evidente, y que poseyendo un comportamiento histórico que es incierto, no previsible y no deducible a partirde su propio pasado, sólo se revela mediante esos datos singulares y privilegiados, mediante esos 'indicios', a aquellas miradas especialmente entrenadas y educadas para descifrar y escudriñar estos mismos datos reveladores. 
Definición del "indicio" en su acepción más estricta, que derriba entonces la falsa idea de que todo hecho histórico o social es un "indicio", y de que toda realidad o proceso histórico social puede y hasta debe ser explicada mediante este paradigma indiciario. Pues es claro que en la sociedad y en la historia existen amplias zonas y vastos conjuntos de hechos evidentes y de realidades obvias y de acceso directo e inmediato a la mirada y al análisis del observador, lo que en este caso hace inútil y hasta ocioso el esfuerzo de detectar indicios, o de aplicar una estrategia indiciaria para su conocimiento o desciframiento específicos.

Pero también se hace claro que, incluso cuando estamos frente a realidades ocultas y de difícil acceso, no cualquiera de sus manifestaciones o expresiones se constituye como un "indicio", sino solamente aquellas que, constituyendo expresiones privilegiadas o especialmente singulares de dichas realidades, se conforman como esos datos agudamente reveladores de la esencia y de la dialéctica profunda de esas realidades. Pues lo real profundo se manifiesta lo mismo en rasgos intrascendentes y realmente accidentales y secundarios, que en otros rasgos más importantes y significativos, los que al condensar en sí mismos la expresión de dimensiones centrales o estructurantes de dicho nivel de lo real profundo, se constituyen en verdaderas llaves de acceso o puntos privilegiados de entrada a dichos núcleos esenciales de la realidad. Y si la microhistoria italiana ha insistido tanto en que los casos que ella elige para investigar como microuniversos históricos, no son los casos estadísticamente "más representativos", sino más bien aquellos casos especialmente reveladores de las realidades esenciales macrohistóricas ${ }^{22}$, así también los indicios en sentido estricto son sólo esos rasgos igualmente reveladores de la realidad oculta, aunque muchas veces estén revestidos de un carácter que sólo en apariencia los presenta como rasgos marginales, accidentales e intrascendentes.

Mas sólo en apariencia, lo que significa que la habilidad para descubrir, ubicar, descifrar y luego interpretar esos indicios no es una facultad innata en los hombres, ni tampoco en los historiadores y científicos sociales, sino que es una capacidad que sólo se adquiere mediante un difícil y complejo

22 Sobre este punto, cfr. Carlo Ginzburg "Microhistoria: dos o tres cosas que sé de ella", antes citado, Giovanni Levi, "Sobre Microhistoria", en el libro Formas de bacer la bistoria, Alianza Editorial, Madrid, 1993, Edoardo Grendi "Microanalisi e storia sociale" en Quaderni Storici, num. 35, 1977, y nuestros textos, Carlos Antonio Aguirre Rojas, "Invitación a otra microhistoria: la microhistoria italiana" y Contribución a la bistoria de la microbistoria italiana, ambos anteriormente mencionados. 
entrenamiento, es decir, mediante un claro proceso de educación de los sentidos, de la razón, de la percepción y de la asociación de todas estas diversas destrezas humanas. Porque del mismo modo en que Engels había ya señalado que nadie nace con la aptitud innata para el pensamiento dialéctico, pensamiento que debe de aprenderse y desarrollarse conscientemente, e igual que la capacidad de detección de las estructuras de la larga duración histórica ha sido una habilidad que Fernand Braudel ha cultivado y ejercitado a lo largo de décadas, así también el hallazgo y la elucidación de los indicios es una capacidad que es necesario desarrollar y cultivar paciente y sistemáticamente.

Cultivo y educación que, por lo demás, y en lo que se refiere a este desciframiento o suerte de lectura de los indicios, no implica sólo el conocimiento teórico o el razonamiento general de lo que ellos son y de los rasgos que los definen, sino también y de un modo esencial e imprescindible, la experiencia práctica reiterada de su búsqueda, su ubicación, su desmontaje y su explicación. Pues no basta la sola vía teórica para adquirir las capacidades de identificación de la autoría de un cuadro, del descubrimiento del criminal, de la detección de la enfermedad en cuestión, o de la aprehensión de la realidad histórica que se nos escapa y esconde al análisis y a la comprensión.

Y si es claro que el saber de las clases dominantes ha tendido siempre más hacia la abstracción y la generalización, y con ello hacia la teoría, mientras que el saber de las clases subalternas, que nace y se recrea constantemente desde ese mundo específico de la experiencia directa, tiende más hacia lo concreto, y lo individual, y con ello hacia las dimensiones prácticas de la realidad, resulta lógico que dicho saber indiciario esté más cerca y tenga una mayor afinidad con la cultura popular que con la cultura hegemónica, sin ser sin embargo para nada patrimonio exclusivo de esa cultura y saber subalternos ${ }^{23}$.

\footnotetext{
23 ¿Quién conoce mejor a la naturaleza, en sus dimensiones concretas y singulares, que el campesino que convive con ella a diario?, ¿y quién sabe más sobre los modos y comportamientos singulares del material y de los objetos fabricados, que sus propios creadores, los obreros de las fábricas?. ¿Y quién conoce mejor la ciudad que sus clases populares, que la viven, la sufren, la gozan, y la crean y recrean cada día sin cesar?. Lo que no impide, naturalmente, que ese conocimiento de la naturaleza, de los productos o de la ciudad pueda ser parcial, incompleto y hasta en parte erróneo, pero igualmente legítimo y fundamental para, como dice Norbert Elias, "orientarse de manera funcional y práctica dentro del mundo", por parte de esas mismas clases subalternas.
} 
Mayor cercanía del paradigma indiciario con esos saberes de las clases subaltemas, que se refuerza por el hecho de que las realidades que son reveladas por los indicios en sentido estricto, no son sólo realidades ocultas y de difícil aprehensión, sino también realidades que se comportan y afirman de maneras inciertas, no predecibles a partir de sus formas de manifestación y de sus itinerarios específicos pasados. Pues a diferencia de ciertas realidades del mundo físico o natural, que repiten y reiteran sus comportamientos mientras se mantienen constantes ciertas condiciones de su equilibrio, las realidades estudiadas por los saberes indiciarios, están en cambio marcadas por una buena dosis de incertidumbre ineliminable. ¿Cómo reaccionarán las masas populares frente a una nueva medida represiva del poder?, o ¿cómo responderá el cuerpo al tratamiento y a las nuevas medicinas suministradas?. Pero también, ¿cómo estará la pesca o la caza de este día, y cómo responderán la madera o el barro, al trabajo del hábil carpintero o del avezado alfarero que los utilizan y moldean?, y ¿cómo juzgar el nuevo caso, pero también como analizar la nueva experiencia histórica bajo examen?. Gracias a los indicios en sentido estricto, pueden responder con buena probabilidad de acertar, el verdadero líder popular o el médico bien adiestrado, lo mismo que el cazador, el pescador, el carpintero, el alfarero, el juez o el historiador, adecuadamente entrenados y educados en la aplicación inteligente y en el uso creativo del paradigma indiciario.

9. Pero si la definición del indicio en sentido estricto es clara, y presenta los rasgos y elementos que ya hemos definido, también es un hecho que es posible hablar de una segunda acepción de este mismo término de indicios, acepción que por lo demás ha sido igualmente utilizada por Carlo Ginzburg, y que nos llevaría entonces a hablar de indicios en un sentido amplio o laxo. Segunda definición posible de los indicios, que siguiendo las lecciones de Marc Bloch, puede explicarse a partir de lo que podríamos llamar la posible lectura indiciaria de la realidad histórica o social, lectura que conecta directamente al paradigma indiciario con el más vasto universo de la tradición del pensamiento social crítico del "largo siglo XX", es decir de los últimos ciento cincuenta años transcurridos ${ }^{24}$, y que es la que lleva a Marc Bloch a afirmar la tesis de que el

\footnotetext{
24 Sobre este punto, cfr. nuestros libros, Carlos Antonio Aguirre Rojas, La bistoriografía del siglo XX, Ed. Montesinos, Barcelona, 2004, Itinerarios de la historiografia del siglo XX, Ed. Centro Juan Marinelo, La Habana, 1999, y Corrientes, Temas y' Autores de la bistoriografía del siglo XX, antes citado.
} 
conocimiento de todos los hechos humanos del pasado y de muchos de los hechos del presente se hace "por medio de indicios", y a Carlo Ginzburg la idea de que "...todos los historiadores trabajan sobre huellas o indicios, e incluso el historiador que escribe una historia política a partir de las actas parlamentarias" 25 . Expliquemos esto.

En el concepto de los indicios en sentido amplio, subyace la idea de que nosotros, los historiadores o científicos sociales, podemos intentar leer e interpretar la realidad que investigamos, y con ello a todos los hechos y fenómenos que nos son accesibles de esa realidad bajo estudio, como si se tratara de indicios en sentido estricto, es decir como otros tantos signos o huellas que ocultan y a la vez revelan a una realidad más profunda. Con lo cual, asumimos que todos los hechos, sucesos y elementos que conocemos y que se manifiestan a nosotros, son en su conjunto toda una serie de diversos "enigmas" por descifrar, y por lo tanto señales, o huellas, o vestigios que nos permitirán acceder a esas realidades ocultas, estructurales y más profundas que intentamos igualmente captar y atrapar. Lo que entonces, convierte en un cierto sentido a todo hecho humano -del pasado o del presente, lo mismo que a todo hecho de cualquier tipo de orden de que se trate, sea político, económico, social, o cultural, lo mismo que geográfico, cósmico, o natural-, en un posible "vestigio" o huella a ser escudriñada e interpretada, es decir en indicios, si bien indicios en un sentido amplio, a los que podrá aplicarse del mismo modo la estrategia cognoscitiva del paradigma indiciario.

Aunque en este caso, es claro que se trata de una suerte de "forzamiento" de la propia realidad, forzamiento que siendo total y absolutamente legítimo como mecanismo cognoscitivo humano, aplica a esa realidad una estrategia de acercamiento y de aprehensión que persigue obligarla a "decir más" sobre sí misma de lo que en principio, o en una aproximación más simple y directa, esta realidad parecería querer mostrar de sí. Forzamiento que asume a cualquier

${ }^{25}$ La cita de Marc Bloch referida, está en el texto del manuscrito titulado "La redacción definitiva", de la Apología para la Historia o el Oficio de Historiador, Ed. Fondo de Cultura Económica, México, 1996, pág. 164 (aunque el epígrafe de todo nuestro ensayo, en donde reproducimos la cita de Marc Bloch sobre este punto, es una traducción nuestra, directa del texto en francés Apologie pour l'Histoire ou Metier d'bistorien, Ed. Armand Colin, París, 1993, pág. 103). La cita de Carlo Ginzburg proviene de su texto "Intervención sobre el paradigma indiciario", en el libro Tentativas, Morelia, ya citado, pág. 161, texto también incluido en este mismo número de Contrabistorias. 
hecho humano como si fuese un verdadero "indicio", y que sigue sin duda los pasos de las lecciones de Marc Bloch en torno de este punto.

Pues en su brillante e inconclusa obra de la Apología para la Historia, Bloch había explicado ya la diferencia entre testimonios históricos voluntarios e involuntarios, señalando como los primeros habían sido directamente producidos o creados para servir como fuentes de un posible futuro historiador, mientras los segundos eran frutos del hacer humano, fabricados para otros fines, prácticos o sociales, pero que al paso del tiempo eran rescatados por esos mismos cultivadores de Clío como posibles fuentes de sus reconstrucciones históricas específicas.

Pero luego de hacer esta distinción, obvia pero importante, entre testimonios voluntarios e involuntarios, Marc Bloch daba audazmente un paso adelante, y planteaba también la idea de que la historia se construía cada vez más mediante una lectura que podríamos llamar lectura explicitadora de los contenidos implícitos, tanto de los testimonios voluntarios como de los involuntarios. Lectura que interrogando de manera oblicua a esos testimonios, estaba concentrada sobre todo en lo que estos últimos "nos dejan entender sin quererlo decir", o dicho en otros términos, una lectura que construida a partir de un cuestionario o encuesta inteligentemente planteados habrían logrado, "saber de él [del pasado a través de sus diversos testimonios] mucho más de lo que había tenido a bien darnos a conocer" ${ }^{2}$.

Entonces, y prolongando esta misma línea blochiana de acercamiento a los hechos históricos y a los hechos sociales, del pasado y del presente, Carlo Ginzburg va a postular lo que podríamos llamar una lectura indiciaria de la realidad, que igual que la lectura explicitadora de Marc Bloch, pretende forzar a la realidad estudiada para obligarla a darnos más de sí misma, y a dejarse explorar y conocer mejor, aunque en este caso, a través de asumir todos los hechos sociales e históricos analizados como si fuesen indicios, o también como indicios en su sentido lato o amplio.

Lo que sin embargo, no impide que Ginzburg perciba claramente la radical diferencia entre trabajar con indicios en sentido estricto, o trabajar con

\footnotetext{
${ }^{26}$ Para estas referencias, cfr. Marc Bloch, Apología para la Historia o el Oficio de Historiador, citado, pág. 171, y más en general pp. 168-176. Véase también nuestro libro, Carlos Antonio Aguirre Rojas, La 'escuela' de los Annales, (7ª edición), Ed. Contrahistorias, México, 2005.
} 
indicios en sentido amplio, al aclarar que los indicios con los que él ha trabajado, y a través de los cuales reconstruyó la cultura popular y las creencias campesinas de los Benandanti o la cosmovisión del molinero Menocchio, son indicios "más indiciarios que las actas parlamentarias" de la historia política, cuya mención hemos referido ya antes ${ }^{27}$. Indicios en sentido amplio, desde los cuales si es posible afirmar que todos los historiadores trabajan con indicios, lo que constituye en parte el origen de la confusión y de algunas malas interpretaciones del paradigma indiciario.

Pero también, y es importante subrayarlo, el desplegar esta lectura indiciaria de la realidad, asumiendo todo hecho humano como indicio, vincula directamente al paradigma indiciario con toda la tradición del pensamiento social crítico contemporáneo, tradición que arrancando con Marx, se prolonga hasta el día de hoy. Pues asumir todo hecho humano como "enigma" o "indicio" a descifrar es asumir frente a él una actitud de "extrañamiento" o de distancia crítica, que rechazando lo evidente y la interpretación habitual y trillada, por obvia, de dicho hecho humano, se pregunta más bien por sus otros posibles significados, por sus mensajes diversos y ocultos, por lo que él puede mostrar o desencubrir de modo alternativo a su inmediatez y obviedad, en suma, por lo que ese hecho social humano puede revelarnos de esas realidades ocultas y profundas, cuando lo abordamos en esa condición de "espía" o "indicio" de dichas realidades.

Actitud del "extrañamiento" que es, ni más ni menos, la actitud crítica ante la realidad, y que al desplazarse de las miradas y visiones habituales de lo real, propias siempre del pensamiento dominante en cada época histórica, son las que observan los hechos de la sociedad y de la historia "a contrapelo" y a contracorriente de las formas tradicionales y tersas de los discursos hegemónicos, haciendo aflorar los pasados vencidos y subterráneos, las causalidades múltiples, las visiones complejas, pero también las explicaciones nuevas, inéditas y radicalmente distintas de las mismas realidades estudiadas. Actitud crítica que ha sido la de Marx, lo mismo que la de Walter Benjamin, Norbert Elias, Marc Bloch, Fernand Braudel, Edward P. Thompson, o Immanuel Wallerstein, entre

37 Cfr. Carlo Ginzburg, "Intervención sobre el paradigma indiciario", en Téntativas, Morelia, ya citado, pág. 163 , y en este mismo número de Contrabistorias. 
otros, y que no casualmente ha sido también teorizada más recientemente por el mismo Carlo Ginzburg ${ }^{28}$.

Punto de vista radicalmente crítico frente a la realidad, que entonces, entre sus múltiples expresiones posibles, tiene también a esta de dicha eventual "lectura indiciaria" de lo real, y por esta vía, la del propio paradigma o estrategia indiciaria del conocimiento.

10. Junto al desciframiento de los indicios en sentido estricto, y a la lectura indiciaria, crítica e intencionada, de los indicios en sentido amplio o laxo, se constituye también, como su prolongación natural y a la vez como su síntesis específica, una verdadera estrategia indiciaria del conocimiento humano de la realidad. Estrategia indiciaria que en su esencia, lo que hace es reivindicar esta vía o camino cognoscitivos de aprehensión de las realidades ocultas y profundas mediante el desciframiento y la lectura de esos "indicios", como un camino tan legítimo, fructífero, válido y productivo, como lo ha sido el camino representado por el paradigma galileano o racionalista del conocimiento, y antes de este último, por el paradigma "platónico" del mismo.

Camino tan válido y pertinente como este último, cuya fuerza y posibilidades heurísticas y cognoscitivas se refuerzan mucho más en la situación que actualmente atravesamos a nivel mundial, en la que los límites de dicho paradigma galileano se hacen cada vez más evidentes, y en la que todas las formas de la racionalidad y del pensar moderno-burgués que corresponden a dicho paradigma racionalista-galileano han entrado en una aguda e irreversible crisis terminal de su propia vigencia, e incluso de su misma existencia y legitimidad históricas.

Pues con la emergencia radical del marxismo, y luego y complementariamente, también del psicoanálisis de Freud, y tras ellos de las

\footnotetext{
28 Cfr. Carlo Ginzburg, "Extrañamiento. Prehistoria de un procedimiento literario" en el libro Ojazos de madera, Ed. Península, Barcelona, 2000, y también "Tolerancia y comercio. Auerbach lee a Voltaire", en Contrabistoricas, num. 1, México, septiembre de 2003. Sólo como posibles ejemplos para esta misma actitud crítica en Marx, a la que puede vincularse además esta lectura indiciaria, cfr. el ensayo de Bolívar Echeverría, "La historia como desencubrimiento", en Contrabistorias, num. 1, recién citada. Y para el caso de esta perspectiva crítica, presente igualmente en la obra de Fernand Braudel, cfr. nuestro libro, Carlos Antonio Aguirre Rojas, Fernand Braudel y las ciencias bumanas, Ed. Montesinos, Barcelona, 1996 (del que existe ahora una versión ampliada en francés, con bibliografía actualizada: Fernond Brandel et les sciences bumaines, que ya hemos citado anteriormente).
} 
múltiples vertientes del pensamiento social genuinamente crítico desarrolladas a todo lo largo del siglo XX, se ha ido haciendo evidente el altísimo precio que la humanidad debió pagar, para afirmar y consolidar a este paradigma de la racionalidad burguesa moderna que tiene en Galileo a su figura emblemática, precio que incluyó la negación del sueño y del deseo, pero también de los instintos, de la afectividad humana, de las emociones, de la sexualidad, y de toda la entera "economía psíquica" de los seres humanos.

Lo mismo que la marginación, el desprecio, la negación y luego la cooptación castrada y deformada de todos los saberes populares y de la riquísima y vasta cultura de las clases subalternas, represión y negación que "desacralizó" brutalmente el mundo para volverlo un mundo poblado sólo de objetos prácticos e instrumentales, pero que también rompió el diálogo, el respeto y el amor del hombre hacia la naturaleza, para degradar a esta última a la vil condición de locus standi y de supuesto reservorio o almacén inagotable de materias primas para el uso y disfrute del supuesto "amo y señor de la naturaleza" que era el hombre. Degradación múltiple de la sexualidad humana, de la economía afectiva del género humano, de las culturas y saberes populares, de la naturaleza, y de todo el mundo práctico de los objetos, que también corre pareja con la marginación y desplazamiento de todas aquellas culturas y saberes no occidentales, no cristianos y no europeos, culturas y saberes que al ser esencialmente disfuncionales al nuevo orden moderno-burgués en vías de mundialización y globalización planetaria, desde el siglo XVI y en adelante, fueron directamente descalificados, combatidos, reprimidos y masacrados, y en algunos pocos casos excepcionales, simplemente ignorados y olvidados.

Y es claro que el paradigma indiciario, en tanto dicha estrategia indiciaria del conocimiento humano, forma parte de esta vasta familia de realidades negadas por el capitalismo planetario, que ahora cumple ya más de cinco siglos cronológicos de existencia.

Pero cuando este capitalismo entra en su crisis terminal, definitiva e irreversible ${ }^{2 y}$,

\footnotetext{
${ }^{29}$ Sobre este punto de dicha crisis terminal del capitalismo, y sobre sus múltiples consecuencias, cfr. Immanuel Wallerstein, La crisis estructural del capitalismo, Ed. Contrahistorias, México, 2005, Después del liberalismo, Ed. Siglo XXI, México, 1996, y Utopística, Ed. Siglo XXI, México, 1998. También nuestros libros, Carlos Antonio Aguirre Rojas, Para comprender el siglo XXI, Ed. El Viejo Topo, Barcelona, 2005, América Latina en la encrucijada, Ed. Contrahistorias, México, 2005, e Immanuel Wallerstein: Crítica del sistema-mundo capitalista, antes ya citado.
} 
lo que ha acontecido después del doble quiebre histórico que representan, tanto la revolución cultural mundial de 1968, como la crisis económica internacional de 1972-73, entonces es lógico que vuelvan a irrumpir con fuerza todas esas múltiples realidades negadas y reprimidas por el capitalismo durante el medio milenio de su existencia histórica. Realidades que al desquebrajarse y aflojarse las estructuras económicas, sociales, políticas y culturales de la modernidad burguesa, pero también y junto a estas, sus estructuras afectivas, familiares, patriarcales, sexistas, racistas y eurocéntricas, van a conocer un verdadero renacimiento y refloración impresionantes, que no sólo las legitiman y revalidan en términos histórico-generales, sino que incluso las relanzan al primer plano de la escena, presentándolas nuevamente como otras tantas formas o rutas posibles de la expresión, de la manifestación, del conocimiento, del vínculo, del acercamiento o de la aprehensión humanos en general.

Revalidación y relegitimación de esos saberes, culturas, actitudes y modalidades del comportamiento no occidentales, no europeas, no cristianas y no dominantes, entre las cuales se encuentra esta reivindicación y reasunción cognoscitiva de las posibilidades y de los frutos de ese paradigma indiciario, de ese saber indiciario de los cazadores, los adivinadores, los marineros, los carpinteros, los médicos, o los jueces y también los historiadores, pero igualmente de las clases populares sometidas y explotadas, de los subalternos en general, de los reprimidos y silenciados por distintas razones, lo mismo que de los rebeldes y los luchadores sociales que se insubordinan y que se rebelan en contra de esta absurda lógica, de esta absurda racionalidad, y de este absurdo orden del capitalismo mundial contemporáneo hoy todavía vigente.

Reivindicación y reasunción del paradigma indiciario que abre entonces todo un complejo universo de preguntas y de temas todavía abiertos, y que apenas afloran hoy para su solución por parte de los historiadores y de los científicos sociales actuales: ¿cómo se conectan en general, y cómo se han vinculado históricamente y de modo concreto, este desciframiento de los indicios estrictos, esta lectura indiciaria de los hechos sociales, y ese paradigma indiciario, con ese saber y esa cultura de las clases subalternas y oprimidas dentro de la historia?, ¿y cómo este desciframiento, lectura y paradigma han sido también expropiados y reapropiados por las clases dominantes, para usarlos en contra de dichas clases sometidas y explotadas?. Pero también, ¿cómo es posible hacer 
dialogar y quizá hasta integrar las conquistas y los avances que implica este paradigma indiciario, con los logros y desarrollos de esa otra forma de racionalidad que es el paradigma galileano?. 0 más ampliamente: ¿cómo recuperar los aportes del paradigma indiciario, más allá del saber y de la cultura populares, sin renunciar a los elementos aún rescatables y legítimos del saber moderno burgués de los últimos quinientos años, en la lógica de la construcción de nuevos saberes y nuevas formas de la cultura humana? ¿Y cómo asimilar dentro de estos nuevos saberes y culturas, hoy de urgente construcción, a los saberes prehispánicos de América Latina ${ }^{30}$, a los saberes orientales, a los saberes africanos, a los saberes musulmanes, entre otros, de todas las civilizaciones y pueblos avasallados y negados por dicho saber eurocéntrico hoy todavía dominante?.

Preguntas vastas y complejas, que derivan claramente de las implicaciones de una lectura seria y atenta del ensayo de Carlo Ginzburg sobre los "Indicios". Y que para su adecuada solución requerirían tal vez, de la escritura no sólo de un ensayo sino de todo un libro. Lo que, en nuestra opinión, explica el hecho de que Carlo Ginzburg hubiese anunciado su texto sobre estos "Indicios", publicado en 1979, sólo como una "versión provisional" de una futura versión definitiva, enfatizando que esta era una "versión ampliada" de su texto publicado en 1978, pero que estaba "todavía muy lejos de ser definitiva". Y aunque Carlo Ginzburg no ha publicado después y hasta hoy dicha versión "definitiva" de su ensayo, sin embargo, y como él mismo lo ha subrayado recientemente, las líneas argumentales principales de este mismo texto del paradigma indiciario, han continuado alimentando y potenciando todo su trabajo posterior hasta ahora concretado.

${ }^{30}$ Sobre este punto, y a título de simple ejemplo, recomendamos ver los libros de Carlos Lenkersdorf, Los hombres verdaderos, Ed. Siglo XXI, México, 1996, y Filosofar en clave tojolabal, Ed. Miguel Ángel Porrúa, México, 2002, libros en donde se muestra la enorme riqueza y complejidad de la concepción del mundo de los indígenas mayas tojolabales, concepción sin la cual es imposible entender de manera adecuada y completa al digno movimiento indígena neozapatista mexicano. Concepción rica y elaborada que, como lo muestra varias veces el autor, y como lo demuestra este digno movimiento neozapatista, puede muchas veces convertirse en una real alternativa de superación frente a la terrible crisis actual de la política moderna, o frente al recalcitrante egoísmo capitalista de las más modernas sociedades contemporáneas, 0 al caos económico y ecológico que producimos y reproducimos cada vez más peligrosamente, 0 a la grave destrucción del tejido social característica de la inmensa mayoría de los países, etcétera, en suma, a la actual crisis terminal del capitalismo mundial que antes hemos referido. 
Si queremos entonces, para terminar, tratar de aplicar en algún sentido este paradigma indiciario para la explicación de la redacción, y luego del impacto mundial del texto "Indicios o espías. Raíces de un paradigma indiciario", quizá podamos preguntarnos: ¿de qué es 'indicio' el texto metodológico de Carlo Ginzburg, publicado primero en 1978 y luego en 1979, y que versa justamente sobre el paradigma indiciario?. Para entonces responder: sin duda, es un 'indicio' de la crisis global de las estructuras generales del saber moderno burgués hoy todavía dominante, pero también es una clara 'huella' o 'indicio' de los múltiples acosos y esfuerzos que, tanto los historiadores realmente críticos, como los científicos sociales que aún intentan pensar la realidad a contrapelo de los discursos hegemónicos, llevan a cabo, en el plano de la historiografía y de las ciencias sociales actuales, para generar y reconstruir las urgentes y muevas formas del saber y del conocer humanos que requerirá y desarrollará esa nueva sociedad, no capitalista, que ya se vislumbra claramente en nuestro cercano y todavía incierto, pero aún altamente esperanzador futuro. 